\title{
Reflexões acerca do processo histórico-filosófico de ruptura entre Homem e Natureza.
}

\author{
Reflexiones sobre el proceso histórico-filosófico de ruptura entre Hombre \\ y Naturaleza.
Thoughts on the historical-philosophical process of rupture between Man and Nature.

\author{
Leandro Lente de Andrade ${ }^{1}$
}

\begin{abstract}
Resumo
O artigo busca produzir uma síntese da problemática ambiental no que diz respeito aos seus entraves com a formação da mentalidade da cultura "ocidental-moderna". Para tanto, são apropriadas as contribuições de distintos autores de diversas áreas do saber, entre eles estão: Fritjof Capra, Keith Thomas, Bruno Latour, Karl Marx entre outros. Não se pretende filiar a uma única vertente de abordagem, justamente por acreditar no diálogo multidisciplinar como parte da luta por unir o vaso quebrado da ciência. Três dimensões do pensamento humano são destacadas: a religião, a ciência e a economia. Além de proporcionar um diagnóstico, o texto também procura levantar, ainda que de modo singelo, alguns pequenos vislumbres de possibilidades basilares para construirmos "novas" formas de pensar a natureza. Como parte dessas possibilidades, o texto fecha mencionando a importância de se incluir a perspectiva socioambiental indígena como vanguarda da luta contra a crise generalizada.
\end{abstract}

Palavras-Chave: Educação ambiental; filosofia; história; homem; natureza.

\section{Resumen}

El artículo busca producir una síntesis de la problemática ambiental en lo que se refiere a sus obstáculos con la formación de la mentalidad de la cultura "occidental-moderna". Para ello, son apropiadas las contribuciones de distintos autores de diversas áreas del saber, entre ellos están: Fritjof Capra, Keith Thomas, Bruno Latour, Karl Marx entre otros. No se pretende filiar a una sola vertiente de enfoque, justamente por creer en el diálogo multidisciplinario como parte de la lucha por unir el vaso quebrado de la ciencia. Tres dimensiones del pensamiento humano se destacan: la religión, la ciencia y la economía. Además de proporcionar un diagnóstico, el texto también procura levantar, aunque de modo sencillo, algunos pequeños vislumbres de posibilidades basilares para construir "nuevas" formas de pensar la naturaleza. Como parte de esas posibilidades, el texto cierra mencionando la importancia de incluir la perspectiva socioambiental indígena como vanguardia de la lucha contra la crisis generalizada.

Palabras clave: Educación ambiental; filosofia; historia; hombre; naturaleza.

\begin{abstract}
The article seeks to produce a synthesis of the environmental problematic with respect to its obstacles with the formation of the mentality of the "western-modern" culture. For that, the contributions of different authors of different areas of knowledge are appropriate, among them are: Fritjof Capra, Keith Thomas, Bruno Latour, Karl Marx among others. It is not intended to join a single strand of approach, precisely because it believes in multidisciplinary dialogue as part of the struggle to unite the broken vessel of science. Three dimensions of human thought are highlighted: religion, science, and economics. In addition to providing a diagnosis, the text also seeks to raise, albeit in a simple way, some small glimpses of basic possibilities for constructing "new" ways of thinking about nature. As part of these possibilities, the text closes mentioning the importance of including the indigenous socioenvironmental perspective as the vanguard of the fight against the generalized crisis.
\end{abstract}

\footnotetext{
1 Doutorando em Educação pela Universidade Federal de São Carlos (UFSCar), Mestre em Educação; Universidade Federal de Alfenas; Alfenas, Minas Gerais, Brasil; leeandroandrade@ hotmail.com.
} 
Keywords: Environmental education; history; men; nature; philosophy.

\section{Introdução}

O título do presente artigo traz o termo "ruptura" como elemento central de uma abordagem histórica. Ao realizar tal inserção dentro do tempo, pressupõe-se que o romper entre homem $^{2}$ e natureza foi um fato ocorrido e que, como veremos, permanece até o presente. Desse modo, está implícita a ideia de que houve um tempo em que não havia um "romper" entre a natureza e o homem como figura integrada. Tentar esboçar o paraíso edênico do passado que precede a cultura hegemônica atual foge completamente os propósitos do presente artigo. Não se trata sequer de pressupor a existência de tal passado harmônico. O ponto aqui é outro. Pretende-se, lendo a atual conjuntura de intensificação dos problemas ambientais, sobretudo após recentes transformações de ordem política, buscar os alicerces que permitiram o desenvolvimento de aspectos que caracterizam e perpassam o modo de vida dito "ocidental". Com isso, a ênfase no rompimento de um suposto elo entre o humano e não-humano não põe em discussão as particularidades dessa relação, mas procura trazer quais elementos constituem a ruptura partindo do olhar dos grupos que contribuíram para a formação do distanciamento. Não se trata de generalizar aspectos culturais, mas de pinçar elementos oriundos de fundamentos religiosos judaico-cristãos que se tornaram predominantes no que hoje se chama cultura ocidental. Em consonância com tais fundamentos, a racionalidade moderna - científica e mercantil - foi se constituindo mediante a centralidade da figura humana (SKINNER, 1999). É, portanto, nessa tripla hegemonia - religião, ciência e economia - que o recorte da noção de "homem" é trazido para reflexão em sua dissonância com a natureza.

Outro conceito que vale ressalvas é a problemática noção de cultura "ocidentalmoderna”. Adota-se esse conceito reconhecendo que a generalização da ideia geográfica de ocidente não representa a totalidade da cultura presente nessa metade do globo terrestre. Assim como se reconhece que esta noção de ocidente também se estende por grande parte do oriente. Trata-se de um conceito atrelado à ideia de cultura, e não geográfico. Desse modo, tomo

\footnotetext{
${ }^{2}$ Ao dizer "homem" me refiro à espécie humana. Não tendo, portanto, a conotação de gênero. Desse modo, não tenho a intenção de isentar a participação da mulher nesse processo de afastamento. Contudo, não seria exagero, em uma leitura superficial da história da relação humana com a natureza que enfatize o desempenho de homens e mulheres, atribuir responsabilidade aos diversos atores homens; ao passo que as mulheres aparecem com certa frequência na luta pela causa socioambiental (ex.: Rachel Carson, Vandana Shiva e Marina Silva). Não obstante, como se verá ao longo do texto, procuro definir esse sentido de humanidade tendo em vista as dimensões religiosas, científicas e econômicas da hegemonia constituída na contemporaneidade.
} 
emprestado de Samuel Huntington ${ }^{3}$ (1997) a perspectiva de ocidental, a qual tem como fundamento os desdobramentos culturais advindos do cristianismo e da organização social greco-romana. Assim, por "mundo ocidental”, entende-se que, em lato sensu, existem certos aspectos comuns dispersos por diversas regiões do globo terrestre, cuja "ocidentalidade" faz presença. A ideia de modernidade, por sua vez, está vinculada à repartição de uma história sob perspectiva europeia. É na profusão do Idade Moderna que a percepção de natureza é intensificada em distância e se dispersa para o além-mar. O movimento renascentista recupera a centralidade do homem, centro ocupado pela divindade por um milênio. Diante do avanço marítimo, das novas descobertas, o ímpeto humano alastra-se em novas terras e rompe os limites naturais de até então. O humanismo invade as esferas religiosas, científicas e marca as novas relações comerciais (SKINNER, 1999, p. 119). É por meio da análise desse período que podemos compreender muito do pensamento hodierno acerca da posição do homem ocidentalizado e a natureza.

Feitas as devidas considerações introdutórias, o artigo pretende colher elementos históricos-filosóficos para realizar uma leitura da atual conjuntura. Em certo sentido, é possível identificar fortes indícios, no presente, que trazem consigo marcas do passado na formação da mentalidade hegemônica. Assim, mobilizar-se-á um conjunto de fatores que, juntos, configuram uma constituição de pensamento que aparta o homem da natureza.

\section{Constituição do pensamento}

Diante de tempos de extremo frio, durante o inverno, é comum ouvirmos o questionamento “onde está o aquecimento global?". Seria uma pergunta honesta, claro. Mas, obviamente, vinda de um chefe de Estado que retirou seu país do Acordo de Paris só pode estar repleta de ironia, revelando seu desdém pelas questões ambientais. Esse foi o tom da pergunta de Donald Trump em sua conta no Twitter. ${ }^{4}$ Qualquer estudante secundarista minimamente atento sabe que tal aparente contradição ocorre pela indistinção entre dois conceitos básicos da

\footnotetext{
${ }^{3}$ Embora algumas afirmações do autor sejam bem discutíveis, como é o caso da negação da presença de civilizações no continente africano e de toda discussão que possa ser feita em torno do próprio checklist civilizacional, a abrangência com que o autor trata a influência de princípios norteadores da coesão ocidental é significativa para que entendamos de que pontos propomos abordá-la.

4 Trump tuitou: "Brutal and Extended Cold Blast could shatter ALL RECORDS - Whatever happened to Global Warming?" em 21 de novembro de 2018. A insistência do presidente estado-unidense em negar o aquecimento global pode ser frequentemente verificada noutros tuites (ex.: 20/01/2019 e 10/02/2019). Aliás, fazer perguntas néscias em redes sociais parece ser uma tendência entre presidentes eleitos pela direita.
} 
geografia, da climatologia: tempo e clima. Além de que a intensificação de temperaturas extremas, incluindo as negativas, é um desdobramento, no tempo, do fenômeno de aquecimento climático global. Em decorrência do degelo do Ártico, as massas de ar frio seguem rumo ao sul, atingindo Canadá e Estados Unidos da América.

Não importa a quantidade e a qualidade da produção científica que afirma o processo vertiginoso de mudança climática, tampouco os estudos que apontam para os efeitos antropogênicos dessas alterações; ${ }^{5}$ o modus operandi anticientífico é um desdobramento da ideologia que insiste em alienar dados concretos, fatos de uma realidade objetiva, renegandoos ao crivo da fé e não da razão. Voltemos a Trump. O presidente republicano rejeitou o relatório que trata detalhadamente dos efeitos catastróficos para a saúde, economia e meio ambiente causados pela alteração climática. O relatório é elaborado pela própria Casa Branca quadrienalmente, e conta com a participação de mais de 300 pesquisadores de 13 agências federais. Ao todo somam-se 1656 páginas rebatidas por Donald Trump com um simples: "Eu não acredito". 6

Procuraremos abordar que, historicamente, o desenvolvimento científico na modernidade não contribuiu para formação de uma racionalidade moderna favorável ao vínculo do homem com a natureza. Não significa pressupor uma perspectiva histórica hegeliana, idealista, linear e unívoca, mas de analisar como a ação de grandes expoentes do pensamento moderno repercutiram na construção da ideia de natureza. São sujeitos históricos que, sem os intuitos de causarem os efeitos ambientais do distanciamento entre homem-natureza, agiram

\footnotetext{
${ }^{5}$ Tomo apenas o exemplo do negacionismo que envolve a temática ambiental, embora reconheça que o caráter anticientífico possa se estender para tantos outros assuntos quanto existirem interesses em contestar aspectos do real já consolidados pela ciência. Já podemos dizer que por décadas a produção científica tem ignorado ou, na melhor das hipóteses, pouco atuado em encarar com seriedade esse fenômeno social. Também não considero como uma característica estritamente nova. A História nos mostra como determinados setores da sociedade possuem reações distintas de acordo com o caminhar da ciência; ora passam por períodos favoráveis, ora "desmentem" e criam suas próprias teorias. A relevância e a urgência em se tratar de assuntos como esse também consiste em compreender que tais assuntos precisam ser trabalhados diante de sua alta adesão do cidadão comum, oriundo de uma baixa escolaridade e distante da "torre de marfim científica". Há tantas outras controversas abordagens anticientíficas que, por rejeitarem a empiria e partirem de posições políticas muito bem firmadas, buscam um arcabouço retórico que as sustentem. Por rejeitarem o que a academia tem oferecido sem produzir uma antítese sob os rigores que a ciência requer, caem muitas vezes na categoria de teorias conspiratórias. Dentre as quais cito como exemplo: campanhas antivacinas; "terraplanismo"; revisionismo histórico que nega o holocausto judeu, o processo violento que envolve a escravidão e o tráfico negreiro; as afirmações que apontam nazifascismo como regimes políticos de esquerda; os esforços por abrandar a ditadura militar brasileira; as recusas aos estudos de gênero; etc. No campo historiográfico, com o qual me familiarizo, é pertinente a leitura dos textos de Enzo Traverso (2007) e Demian Melo (2013). Por fim, em paralelo à necessidade da academia em levar a sério esses temas, também defendo a aproximação de toda essa produção de conhecimento junto à população. Caso contrário, como cientistas permaneceremos em nossos "icebergs" enquanto ainda os temos.

${ }^{6}$ Ver artigo do dia 27 de novembro de 2018 no Jornal Online El País: Trump sobre relatório climático do seu Governo: "Não acredito" (MONGE, 2018).
} 
diante das condições específicas de seu tempo. Os grandes "epistemólogos" da modernidade (Nicolau Copérnico, Galileu Galilei, René Descartes, Francis Bacon, David Hume e Isaac Newton), todos, de diferentes modos contribuíram para distanciar o sujeito do objeto, fragmentar o mundo, exercer o domínio do homem, romper com as relações de causalidade e tornar o mundo mecânico. Assim, o exemplo da liderança estadunidense é curioso, pois negase a ciência quando ela oferece um retorno para integrar as partes ao todo. Nega-se a relação que há entre as ações humanas e seus reflexos no meio ambiente. Nega-se a ciência, justamente, quando ela proporciona um diagnóstico global integrado às ações humanas. Parece-nos que, para "fazer a América grande novamente", é necessário diminuir a ciência e todo o resto do mundo. ${ }^{7}$

Dividimos esta seção em três pontos principais, cada qual abordando uma das diversas dimensões que constituem parte do pensamento "ocidental moderno". No primeiro momento, trata-se do que poderíamos chamar de pensamento "religioso", embora, saibamos que o religioso nunca está fadado a isolar-se. Desde o pioneiro trabalho de Max Weber (2007), compreendemos que o modo religioso interfere na ação social dos indivíduos, invadindo as esferas econômica, política e outras. O segundo ponto visa tratar do que por muito tempo pensou-se ser o substituto para a religião: a ciência. A fragmentação do pensamento moderno, por sua vez, está longe de resumir-se à objetividade tão desejada pela ciência. Ao contrário, toda produção científica está engajada em seu uso social e, portanto, adentra à esfera política. Por fim, abordo o capital como elemento fundamental para compreender a exploração da natureza como recurso e as organizações socioespaciais desiguais como consequência do modo de produção capitalista.

Como vimos anteriormente, a posição de Donald Trump quanto ao aquecimento global é exemplo de como esses três fundamentos do pensamento contemporâneo mesclam-se. Na intenção de tornar o texto mais "didático" possível, opta-se por dividi-lo nos três pontos mencionados - religião, ciência e economia - enfatizando suas diferentes origens e pressupostos, sem, no entanto, desconsiderar a sua atual capacidade de penetração entre si.

\subsection{O fundamento judaico-cristão do domínio}

\footnotetext{
${ }^{7}$ Além do mais, o slogan de propaganda política dos republicanos promete a grandeza americana sob a égide da economia imperialista e, obviamente, não envolve tantos outros aspectos cuja pequenez é acentuada.
} 
et ait: Faciamus hominem ad imaginem et similitudinem nostram: et praesit piscibus maris, et volatilibus caeli, et bestiis, universaeque terrae, omnique reptili, quod movetur in terra. (GENESIS 1:26)

A narrativa cosmogônica do livro do Gênesis parte de uma perspectiva sui generis em relação à temporalidade e à condição da criação. A criação divina inicia-se com um estado de perfeição, plenitude e harmonia; mas que não tarda em ser corrompida pela má escolha humana diante do seu livre-arbítrio $\left(\mathrm{Gn}^{8} 3\right)$. $\mathrm{O}$ “estado de queda" põe fim à situação paradisíaca vivida pelo homem e a natureza. Com o pecado é inaugurado um período de suor e dor para toda a criação. ${ }^{9}$ Daí a tão esperada redenção da alma humana e da matéria pervertida pelo pecado. A razão da instauração da problemática ambiental, segundo o pensamento judaico-cristão, consiste em responsabilizar o homem por suas más escolhas, proposta apologética agostiniana para o problema do mal/sofrimento e sustentáculo basilar para o pensamento cristão atual (AGOSTINHO, 1995).

No entanto, cabe-nos colocar em evidência os pressupostos que fazem com que uma decisão humana acarrete no preço a ser pago por toda a natureza criada. A figura humana é tratada com alta distinção desde sua criação. O homem é o único ser da criação que possui traços da própria divindade. Diante de toda a natureza, é somente ele quem carrega a imagem e semelhança do Supremo, ao passo que a criação apenas revela as obras da mão divina (Sl 19:1). Aliado a esse valor ontológico superior, a humanidade é incumbida de cumprir a expressa ordem de dominar os demais seres (Gn 1:26-28). Dessa forma, o distanciamento da espécie humana das demais precede a origem do descompasso causado pelo pecado. Já há uma assimetria de caráter ontológico na atribuição de valores distintos entre humanidade e natureza. Essa nítida hierarquização é o fundamento sob o qual impõe-se à natureza o sofrimento oriundo da má escolha humana no Éden.

É o fruto da árvore a causa primeira do problema, a serpente como causa segunda, e a mulher, Eva, como terceira responsável na genealogia do surgimento mal. É emblemático que

\footnotetext{
${ }^{8}$ As siglas referentes aos livros bíblicos seguem o padrão utilizado nas versões da Bíblia de Jerusalém em Português.

${ }^{9}$ Por todo o livro sagrado cristão é relatada a decadência da natureza como consequência da ação humana: o solo foi amaldiçoado (Gn 3:17); a primeira morte animal é registrada como consequência da medida tomada por Deus para cobrir a vergonha humana (Gn 3:21); Deus se arrepende da criação (Gn 6:5-7) etc. No Novo Testamento fica clara a necessidade de redenção não somente humana, mas da natureza: "a criação aguarda ansiosamente a manifestação dos filhos de Deus. Pois a criação foi sujeita à vaidade \{não voluntariamente, mas por vontade daquele que a sujeitou\}" (Rm 8:19,20).
} 
uma narrativa cosmogônica, responsável por fundar a mentalidade das três maiores religiões monoteístas, distribua a causalidade do surgimento do mal nos seres não humanos e não masculinos: o vegetal, o animal e a figura da mulher. Tal narrativa viria a se tornar âncora de todo cânone pentateuco, o Torá hebraico, das Escrituras Sagradas cristãs, além de influenciar a versão análoga do islã no Alcorão. Portanto, o estado de harmonia, plenitude e bondade que outrora reinava nos primeiros dias da criação é interrompido pelo advento do mal em decorrência da queda humana. É a partir de então que a narrativa bíblica inicia os meandros de um caminho tortuoso que não envolve apenas a espécie humana, mas toda a criação divina e, com isso, o meio ambiente é incluso como parte dos problemas que refletem a quebra no equilíbrio original. ${ }^{10}$

O historiador britânico Keith Thomas (1988) condensa uma ampla quantidade de documentos do medievo e da era moderna para corroborar com a tese de que a formação da sociedade europeia-cristã se constituiu de acordo com fundamentos teológicos. Desde a patrística até os pensadores humanistas cristãos do renascimento, há a mescla das bases religiosas com os pensadores clássicos da interpretação sobre a espécie humana. Para exemplificar, a escolástica recupera o argumento aristotélico do zoon politikón para destacar a distinção humana das demais espécies, aliando-o à singularidade da centelha divina da razão para gerir seu o governo secular. Não obstante, mesmo as alas mais radicais dos humanistas críticos da filosofia vinculada à tradição cristã, nunca negaram a distinção entre homem e natureza, apenas a afirmavam por vias distintas (SKINNER, 1999, p. 108).

Não é por menos que tenha cabido ao cristianismo ocidental o rótulo de religião mais antropocêntrica do mundo (WHITE JR., 1967, p. 1205). Seria, então, o cristianismo a principal causa da mentalidade da "cultura ocidental" responsável pelas grandes mazelas ambientais? É o pensamento cristão responsável pela ideologia impeditiva de levarmos a sério a urgência dos assuntos relacionados à natureza? Por ventura a destruição da vegetação, a extinção de espécies, o descaso com o aquecimento planetário, a irresponsável extração de recursos naturais finitos, entre tantos outros problemas, teria como fundamento as narrativas que, ao passar dos anos, foram compondo uma tradição religiosa?

Para Keith Thomas, não. Embora o cristianismo tenha participação nessa teia cultural, “os problemas ecológicos não são exclusivos do Ocidente, pois a erosão do solo, o

\footnotetext{
${ }^{10}$ Ver nota 8.
} 
desmatamento e a extinção de espécies tiveram lugar em partes do mundo onde a tradição judaico-cristã não teve qualquer influência" (THOMAS, 1988, p. 29). ${ }^{11}$ Ademais, em se tratando de constituição da mentalidade religiosa, outros povos também desenvolveram narrativas cosmogônicas que propõem a distinção do homem e o colocam em posição de autoridade diante dos demais seres.

É verdade que o status quo de superioridade e domínio do humano sobre os nãohumanos não é exclusividade da perspectiva judaico-cristã de mundo. Assim como também procede o fato de que há dentro do cristianismo ocidental - católico e protestante - uma enorme variedade de olhares ambientais (HARRIS, 1938; BOFF, 1999; JONES, 2008; BONTEMPO, 2011). O próprio historiador Lynn White Jr., responsável pelo clássico artigo que culpabiliza o cristianismo ocidental pela crise ecológica, reconhece na Ordem franciscana o pensamento contraditório da ortodoxia predatória romana (WHITE JR., 1967, p. 1206-1207). Todavia, a multiplicidade de perspectivas teológicas cristãs acerca da natureza e a existência de outras formas de organização social pautadas na exploração da natureza, fundamentadas noutras religiões ou não, não amenizam a incisão da herança judaico-cristã tradicional na dita "cultura ocidental" e na sua relação predatória diante da natureza.

\subsection{Cartesianismo da ciência}

O mundo hodierno tem a ciência como a antítese da religião. É inegável a busca por procurar manter distante ou suspender a fé religiosa na apropriação de um determinado objeto de pesquisa, na escolha do aporte teórico-metodológico e na análise dos resultados, por exemplo. Faz parte da utópica busca pela neutralidade científica. Esse esforço por dissociar a ciência da religião se estende para fora dos laboratórios e alcança a divulgação científica e seus

\footnotetext{
${ }^{11}$ Como resultado da profunda interferência humana com o meio, no uso não sustentável do solo, inviabilizando o reestabelecimento produtivo básico para sobrevivência, entre outras razões, algumas dessas populações teriam entrado em colapso. Essa é uma das teses defendidas pelo autor de diversos best-sellers chamado Jared Diamond. Tal discussão retoma os debates ocorridos no fim do século XIX entre os geógrafos Friedrich Ratzel e Paul Vidal de La Blache, os quais foram os principais expoentes das vertentes definidas pelo historiador Lucien Febvre como "determinismo" e "possibilismo", respectivamente (MORAES, 2005, p. 67-101). Essa ênfase nos fatores ambientais como cruciais para a possível derrocada de algumas sociedades é ressuscitada por Diamond (2005). No entanto, a grande parte da historiografia tem procurado demonstrar como essas ondas de apogeu e declínio tiveram dimensões muito mais complexas do que a mera constatação de um colapso definitivo relacionado ao (mal) uso dos recursos naturais. Sobre o caso maia, em específico, o declínio populacional em alguns dos principais centros cerimoniais do período clássico, é explicado tendo em vista o grande fluxo migratório para outras regiões, sobretudo ao norte das terras baixas de Iucatã, e a alternância de certas hegemonias políticas para outros centros (NAVARRO, 2008, p. 363-372).
} 
meios mais comuns de retorno à sociedade: a Educação Básica. Não são poucos os temas em que a ciência apresenta suas teorias e entra em conflito com perspectivas religiosas.

Contudo, historicamente, a gênese da ciência moderna carrega marcas da curiosidade humana instigada pelo desejo de conhecer a obra do seu Criador. Os primeiros filósofos da modernidade, embora rompessem com a "tradicional epistemologia", mantiveram uma série de perspectivas antropocêntricas oriundas de uma sociedade calcada na crença da superioridade humana, de raízes teológicas. Há uma continuidade da discussão metafísica e uma reestruturação de aspectos filosóficos de natureza racional teológica, ao passo que o mundo passa por um processo de matematização do real (OLIVEIRA; ALMEIDA, 2003). Esse novo modo de compreender a lógica por detrás da existência das coisas, ainda tendo em vista uma força inteligente formuladora de leis para o seu funcionamento, dará forma à ciência moderna e contribuirá singularmente para a dilatação do abismo entre homem e natureza.

Com advento das novas bases para a ciência, a relação sujeito-objeto é posta em evidência e pensada por praticamente todos os filósofos modernos. O homem como sujeito estava dando largos passos para desvincular o sentido harmônico que o restante do mundo material, físico, havia tido no pensamento escolástico. Se agora havia harmonia entre os seres existentes, não estaria atrelada aos fundamentos aristotélicos e teológicos tomistas da essência e teleologia dos seres. A razão da harmonia estava posta pela autonomia que a filosofia moderna desenvolvera em permitir-se estudar o mundo natural a partir de novos parâmetros, sob um novo método que privilegiasse a capacidade humana de elaborar explicações sem a tutela da tradição.

Lento, mas com profundidade, o processo de distanciamento entre o sujeito e o objeto, a cultura e a natureza, entre a cidade e o meio ambiente, vinha dando forma ao modo de viver na Europa. René Descartes decompôs os objetos da razão, por meio de um novo método científico fragmentado; o empirista Francis Bacon foi o pioneiro a defender o conhecimento sobre a natureza como meio para seu domínio, afinal, "saber é poder" em sua concepção; Galileu Galilei levantou um novo paradigma, uma "revolução científica", ao distanciar o sujeito do objeto, apontando que quem define a verdade científica objetiva é a perspectiva do sujeito enquanto observador externo; e Isaac Newton tornou a natureza mecânica, ao elaborar suas famosas "leis". No campo científico que trata da temática ambiental todo esse movimento gerador de uma "cultura ocidental" é denominado como "cartesianismo" e caracterizado como "reducionista, fragmentário, sem vida e mecânico" (GRÜN, 2009, p. 61). 
Como desdobramento do forte movimento ocorrido na segunda metade do século XVIII, o Iluminismo, com sua razão científica de caráter expansionista civilizatório, contribui para a formação de profundas marcas no pensamento contemporâneo. A herança desses movimentos processuais histórico-filosóficos, tornados grandes marcos da história, é, em certo sentido, hegemônico na constituição das ideias contemporâneas. Embora o romantismo do século XIX tenha abarcado também aspectos científicos cautelosos, integrando a infinitude da natureza e a limitação humana - em contraponto ao otimismo iluminista -, o movimento perdeu força diante da forte noção de progresso trazida com o positivismo. Posteriormente, diversos aspectos e modos científicos voltariam a sofrer novos questionamentos no período pós-guerra, mas a natureza das questões não traria grandes alterações no modo com que entendemos o meio natural (REALE; ANTISERI, 2005).

Ainda há duas observações a serem feitas a respeito da ciência e suas dimensões ambientais. A primeira delas consiste na cooptação da problemática ambiental. Oriunda da limitação consolidada pelo abismo entre homem e natureza, o modo ocidental de pensar ecologicamente não rompe com essa dicotomia, tampouco deixa de evidenciar o domínio do homem sobre o meio. Afinal, essa ecologia "rasa" sustenta em sua base a clara noção de que se preservamos a fauna e a flora é porque estamos na condição de agentes dominantes. Não se trata de uma "ecologia profunda", nos termos de Fritjof Capra (1996), mas de uma ecologia antropocêntrica. Segundo ele, essa ecologia "vê os seres humanos como situados acima ou fora da natureza, como a fonte de todos os valores, e atribui apenas um valor instrumental, ou de ‘uso', à natureza” (CAPRA, 1996, p. 14).

Seria ingenuidade compreender a ciência como neutra e desvinculada do humano. A ciência contemporânea não está isolada das suas dimensões políticas e discursivas (LATOUR, 1994). Este é o segundo ponto. Bruno Latour desenvolveu reflexões pertinentes acerca da epistemologia de nosso tempo como fruto da modernidade. Embora procure definir o termo "moderno" dentro de seus pressupostos, o autor francês também realiza uma contundente crítica ao que convencionou-se chamar de modernidade. A hipótese de Bruno Latour é de que a modernidade se caracteriza por dois grandes fatores: 1) "tradução", que comporia o hibridismo presente entre natureza e cultura; e 2) "purificação", separando o humano do não-humano. Para que essas configurações permanecessem válidas para nossa sociedade, ambas deveriam permanecer distintas. No entanto, como ele observa, "recentemente deixaram de sê-lo" (LATOUR, 1994, p. 16). Desse modo, Latour expõe uma série de contradições presentes nessa 
definição particular de moderno, para afirmar a hipótese de que jamais fomos modernos; e, consequentemente, levantar como outras possibilidades de compreender o mundo e produzir ciência passariam a ser possíveis.

Não é à toa que o autor, trazendo uma abordagem ímpar, promova um ensaio propositivo no qual levante como hipótese um novo modo de interpretar (e de politizar) o mundo atual: por meio da simetria entre humanos e não-humanos. Dessa forma, Latour propõe que não isolemos os elementos objetivos da "ciência laboratorial" sem que se pense na complexa rede de significados que tais conhecimentos trazem para outras dimensões da humanidade. Assim, não haveria produção de conhecimento científico sem que adquirisse dimensões políticas e perpassasse por tantas outras áreas especializadas do campo científico. O buraco na camada de ozônio, por exemplo, ao mobilizar uma variedade significativa da realidade objetiva - tal como os gases de clorofluorcarbonetos (CFCs), mas também, o derretimento das calotas polares, a alteração dos níveis do mar, os problemas de saúde resultantes dos raios solares, a indústria de aerossóis, refrigeração etc. - não mobilizaria apenas químicos, mas meteorologistas, geógrafos, economistas, profissionais da saúde, ambientalistas e políticos.

Ambos os autores acima mencionados, Fritjof Capra e Bruno Latour, cada um a seu modo, identificam o problema da fragmentação em partes provocado ao longo da história da ciência. Tais constatações refletem no olhar que dirigimos aos seres não-humanos e em como nos relacionamos com eles. As análises da filosofia da ciência elaborada pelos autores adentram à epistemologia de seu tempo e propõem novos modos de enxergar os elos entre o homem e o artificial isolamento das coisas. Não obstante, as contribuições de tais autores possuem uma forte dimensão para as discussões de ordem ambiental no que tange a participação do olhar científico para a problemática.

Em suma, parece-me ser necessário considerar modos de produção científica que possibilitem a compreensão do mundo desprendidas do antropocentrismo. Se por um lado a ciência tem como eixo produtor o homem - afinal toda ciência é, por natureza, humana -, podemos pensar em como nos articulamos com nossos "objetos" de pesquisa. A relação entre sujeito e objeto compõe parte intrínseca da ciência, mas a forma com que se dá essa relação é algo a ser problematizado, tendo em vista a apropriação de seus objetos, dentre eles a natureza, como um recurso para atingir outros fins. 


\subsection{A centralidade do capital}

Os rumos que a economia tomou desde os primórdios do mercantilismo agravaram a exploração da natureza. O período de expansão marítima encontrou a possibilidade de aumento territorial europeu no processo de colonização que atingiu as Américas. Tais fatores históricos, aliados da ambição por angariar recursos tão almejados pelos reinos do Velho Mundo, resultaram na intensificação da alienação do homem e sua relação com a natureza. A ausência de uma consciência voltada para os limites do meio físico, própria de um período de crescimento dos horizontes de exploração, atenua a sensibilidade humana no relacionamento com o mundo ao seu redor. O crescimento do poder do capital no desenvolvimento da sociedade ocidental é causa das centenas de conquistas humanas, ao passo que o meio ambiente é lastimadamente levado à cabo apenas como meio para os fins de progresso e acúmulo. As revoluções industriais são exemplo de uma completa apropriação da natureza e da atribuição de um novo valor em prol do avanço, um valor de caráter primariamente econômico.

Cabe-nos aqui abordar, tal como no seio do religioso e do científico, de que maneira a dimensão econômica contribuiu para o afastamento entre homem e natureza. Noutras palavras, trata-se da análise do sistema capitalista que adentre pelos pressupostos filosóficos, identificando teoricamente as causas de uma possível quebra do vínculo relacional entre homem, absorvido pela lógica capitalista, e aquilo que é externo a ele. Dessa forma, o estado de alienação do homem não se restringe ao trabalho, nem às relações entre si em sociedade, mas se estende à natureza. Portanto, recuperaremos a antiga noção de metabolismo no pensamento marxiano.

Karl Marx, ao utilizar-se do conceito de metabolismo empregado à sociedade, faz menção ao vínculo que há entre o homem e a natureza mediado pelo trabalho. Assim, o trabalho, em sua perspectiva, consiste na apropriação da natureza, modificando-a, e projetando seu modo de vida; para que, por fim, o fruto de seu trabalho seja condizente com a utilização do resultado por seu produtor. No entanto, quando o trabalho passa a servir a outra função, que não diz respeito ao homem que exerceu sua força de trabalho, este torna-se alienado. Uma vez alienado aquilo que media a relação homem e natureza, o próprio trabalho, esta relação passa a também estar sob alienação (FOSTER, 2010).

Nesse sentido, segundo Marx (1844), há uma fratura/ruptura/falha metabólica que divide homem e natureza, causada originalmente pela alienação do trabalho. Não obstante, 
estudos desenvolvidos a partir dessas categorias apontam que quaisquer que sejam as formas de propor uma saída para a crise ambiental, caso não proponham a superação da alienação do trabalho, estarão fadadas à insustentabilidade ambiental dos projetos desenvolvimentistas. Assim, "a superação da alienação dos homens com o trabalho e com o meio exterior (natural) que o cerca é um desafio para a sociedade que objetiva desenvolver-se de forma socialmente sustentável" (FREITAS; NÉLSIS; NUNES, 2012, p. 48).

Não obstante, a exploração da natureza reflete a forma com que nos relacionamos entre nós, humanos. Afinal, a noção de fratura metabólica tem como causa a condição alienada do homem, do trabalhador explorado. Alheio ao metabolismo de outrora, o homem passa a compreender a natureza como um recurso inesgotável e, como consequência da atribuição de valor de troca à natureza - e não o valor de uso -, tendo em vista o lucro, o modo de produção capitalista ruma não apenas para a crise ambiental, mas também à crise do próprio capital. A própria finitude dos recursos limita a contínua expansão econômica, levando a exploração a outras regiões em busca de dar seguimento, a todo custo, à produção de excedente (MONTIBELLER FILHO, 1999, p. 159-161).

Ao tratar da acumulação primitiva, Marx (2006, p. 825-858) lista o processo de acumulação por espoliação, no qual podemos traçar a "mercadificação" tanto da força de trabalho quanto da própria terra. Nesse sentido, segundo Harvey,

A escalada da destruição dos recursos ambientais globais (terra, ar, água) e degradações proliferantes de hábitats, que impedem tudo exceto formas capitalintensivas de produção agrícola, também resultaram na mercadificação por atacado da natureza em todas as suas formas (HARVEY, 2005, p. 123).

Assim, ocorre a transformação do sentido de natureza, que outrora compôs parte integrante do modo de vida do homem ao suprir suas necessidades vitais por meio do trabalho, para sua noção mercadológica capitalista. ${ }^{12}$

Portanto, a perspectiva crítica, de origem marxista, da questão ambiental é marcada como uma recusa aos elementos centrais da sociedade capitalista. Tem como alvo a alienação

\footnotetext{
12 "Marx compreendeu perfeitamente, já naquela altura [anos 40 do século XIX], que uma reestruturação radical do modo predominante de intercâmbio e controle humano é o pré-requisito necessário para um controle efetivo das forças da natureza, que são postas em movimento de forma cega e fatalmente autodestrutiva sobretudo em virtude do modo predominante, alienado e reificado de intercâmbio e controle humanos. Causa, portanto, pouca surpresa o fato de o diagnóstico profético de Marx ser considerado pelos atuais apologistas do sistema de controle estabelecido nada mais do que um "anacronismo paroquial' (MÉSZÁROS, 2011, p. 53)
} 
do trabalho, o modo de produção predatório, a noção de natureza como recurso inesgotável, o estímulo ao consumo exacerbado, o lucro a qualquer custo etc. Trata-se de um sistema de crucial contradição: a irracionalidade do racional. Se, por um lado, há o aprimoramento racional de todo conjunto de elementos encadeados visando a produção e consumo, por outro, o sistema capitalista parece não considerar as suas últimas consequências: o colapso ambiental, econômico e humano. Trata-se de um "efeito cascata" irremediável que torna toda suposição de desenvolvimento sustentável, no interior do capitalismo, totalmente inviável de modo permanente. Por hora, pode até ser apontada como um desenlace que se sustenta por certo período, mas a permanência da lógica do modo de produção capitalista perpetua a perversidade da cisão metabólica, que deve ser superada. Tal contradição é apontada por István Mészáros (2011, p. 51-54). Para além da inexorável crise oriunda da exploração da força de trabalho, já levantadas por Marx, a crise do capital também se dá pelos limites impostos pela própria natureza dada sua finitude. Isso implica em compreender que as evidências de crise ambiental são, em última instância, sinais que apontam para uma crise estrutural do capital. "Não obstante," conforme apontam Ana Carolina Quintana e Vanessa Hacon, "atualmente a degradação da natureza em ritmo acelerado agudiza ainda mais as velhas contradições do capitalismo, colocando em xeque a sua própria sobrevivência" (QUINTANA; HACON, 2011, p. 439).

\section{Por "novas" formas de pensamento}

A recente manifestação da crescente ala conservadora e liberal, por diversos países pelo mundo, explicita o fundamentalismo religioso, o ímpeto do progresso e a ilusão da prosperidade ilimitada no livre mercado. Seria possível, dentro dos moldes de pensamento hegemônico, superar essa crise? Há quem diga que sim. Grande parte dos movimentos ambientalistas depositam a esperança na tarefa hercúlea de tornar o mundo um lugar melhor sem romper com a racionalidade "ocidental-moderna". O acesso em massa à informação acerca dos problemas ambientais causados pelo homem; a tendência de um novo padrão de consumo, uma "moda verde"; e o aprimoramento tecnológico que reduz o nosso impacto sobre a natureza, substituindo as antigas tecnologias, todos são elementos que alimentam esse grande otimismo e projetam o desejo de um desenvolvimento sustentável, sobretudo, para um futuro no qual as novas condições trazidas pelo tempo viabilizariam a permanência das mesmas formas de pensamento. 
Diariamente somos bombardeados com manchetes de jornais alertando para o uso irresponsável dos recursos minerais, da falta de tratamento adequado de água, do impacto causado pelo destino dos resíduos, do aquecimento global, do buraco na camada de ozônio, da contaminação e desmatamento de ambientes naturais. Isso não significa que o acesso em massa à informação gera consciência ambiental. Nos acostumamos com a violência humana na degradação do planeta. Informação, somente, não gera consciência cidadã e não implica em ações de combate aos impactos ambientais. A informação, em si, simplesmente pode acarretar em ações ainda mais predatórias. A finitude da água, por exemplo, é informação válida; mas, se não observada diante de uma perspectiva distinta que gere uma práxis transformadora, permanece ausente de consciência ambiental. A água permanece sento entendida como recurso hídrico sob o qual a mobilização de diversos setores da sociedade que passa a agir tendo em vista a informação, mas sem que haja uma mudança de cunho ontológico no que venha a ser água. A informação não significa necessariamente que resulte práticas políticas, conscientes ambientalmente, de tratamento de água, controle, fiscalização agropecuária e industrial, e uso racional doméstico. Assim, o sentido de "conscientização" empregado na Educação Ambiental Crítica no ambiente escolar, por exemplo, deve encontrar na informação um dos elementos necessários. Tal como aponta Loureiro:

conscientizar só faz sentido se for no sentido posto por Paulo Freire de "conscientização": de processo de mútua aprendizagem pelo diálogo, reflexão e ação no mundo. Movimento coletivo de ampliação do conhecimento das relações que constituem a realidade, de leitura do mundo, conhecendo-o para transformá-lo e, ao transformá-lo, conhecê-lo. Dinâmica escolar que reconhece as especificidades de professores, pais, alunos e demais integrantes da comunidade escolar, mas que não pensa o acesso à informação e à cultura dissociada da contextualização da prática e da recriação da própria cultura. (LOUREIRO, 2007, p. 70)

Portanto, a informação sobre a escassez da água, se não acompanhada de uma outra forma de compreender o mundo e agir nele, pautada no coletivo, na boa administração do que é público, com valores de solidariedade e que repense o sentido e o valor da água, resultará em ações que visem o acúmulo desse "bem" para fins mercantis e geopolíticos. Essa informação, sob as antigas formas de compreender o mundo, o que nele existe, e as relações humanas, acarreta em ações voltadas para o individualismo, o lucro, a exploração, e até mesmo a guerra diante da escassez.

Quando a crise ambiental é abordada no intuito de pensarmos soluções, nem sempre identificamos exatamente sob quais fundamentos estão assentados as argumentações, os interesses, as ações e os seus possíveis resultados. Há algum tempo, já se tem apontado como 
o discurso de "desenvolvimento sustentável" marca presença em políticas autoritárias que maquiam suas reais intenções na apropriação de jargões ecologicamente bem quistos. Dessa forma, empresas têm adentrado pelo caminho da sustentabilidade, adquirindo uma imagem de "consciência verde", de pureza e imácula, enquanto permanecem à serviço do capital (PELICIONI, 1998). Uma empresa, ao notar que o papel reciclado adquiriu maior valor de mercado, procurará investir na produção desse material apropriando-se de papel virgem, o que seria um desastre ainda maior. Tal é o exemplo dado por Mauro Guimarães, em que conclui dizendo: "é preciso, então, criticar a lógica e os valores das sociedades modernas para que possam realmente ser criadas uma tecnologia 'limpa' e um modelo não destrutivo do meio ambiente" (GUIMARÃES, 2000, p. 34, grifo meu).

Desse modo, a solução para a crise ambiental consiste, sobretudo, na superação do sistema capitalista. Somente o desenvolvimento de tecnologias limpas e a mera mudança comportamental não alteram as estruturas que, em última instância, são as reais causadoras dos problemas ambientais. Assim sendo, seria necessária uma "reorganização da base civilizacional e da estrutura política, econômica social e cultural" (LOUREIRO, 2006, p. 11).

Se aliada dos mesmos modelos de pensamento, a informação pode não servir para a criação de uma consciência ambiental. $\mathrm{O}$ avanço tecnológico, embora possa ter papel importante para elaborarmos novas possibilidades, também não é garantia de uma relação sem o domínio perverso do humano (além de reforçar a noção de superioridade e controle sobre a natureza). E, por fim, mesmo que a conscientização alcance grande parte da população, a apropriação do discurso de sustentabilidade assentado sobre a antiga forma de pensar fará com que os detentores dos meios de produção cooptem a noção de "desenvolvimento sustentável" (e outras que poderão vir no futuro) para alcançar o excedente por meio dos seus produtos "ecologicamente corretos".

Nesse sentido, diversos autores dedicados à temática ambiental engrossam o coro pela instituição do "novo". Vilmar Berna e Marcos Reigota, grandes expoentes da Educação Ambiental no Brasil, têm trabalhado a importância de uma transformação ética alicerçada no exercício da cidadania. Berna escreve:

O ensino sobre o meio ambiente deve contribuir principalmente para o exercício da cidadania, estimulando a ação transformadora, além de buscar aprofundar os conhecimentos sobre as questões ambientais de melhores tecnologias, estimular a mudança de comportamentos e a construção de novos valores éticos menos antropocêntricos (BERNA, 2001, p. 18, grifos meus). 


\title{
E Reigota:
}

\begin{abstract}
O meio ambiente latino-americano exige que a educação ambiental enfrente o desafio da mudança de mentalidade sobre as ideias de modelo de desenvolvimento baseado na acumulação econômica, no autoritarismo político, no saque aos recursos naturais, no desprezo, às culturas de grupos minoritários e aos direitos fundamentais do homem [...]. [Essa] educação política deve estar empenhada na formação do cidadão nacional, continental e planetário baseando-se no diálogo de culturas e de conhecimento entre povos, gerações e gêneros (REIGOTA, 1995, p. 25, grifo meu).
\end{abstract}

Contra o cartesianismo, "precisamos de um modelo ou matriz normativa que não seja reducionista, fragmentário, sem vida e mecânico, mas que seja complexo, holístico, vivo e orgânico", afirma Mauro Grün (2009, p. 61). Não é algo simples. Trata-se de repensar novas bases para a ciência que fundamentem toda nossa forma de interpretar e viver com a natureza que recusem os fundamentos do pensamento científico moderno. O ponto de mutação viria acompanhado da "ecologia profunda" a qual, segundo Capra, trata de um "novo paradigma" holístico que

não separa seres humanos - ou qualquer outra coisa — do meio ambiente natural. Concebe o mundo não como uma coleção de objetos isolados, mas como uma rede de fenômenos que estão fundamentalmente interconectados e são interdependentes. A ecologia profunda reconhece o valor intrínseco de todos os seres vivos e concebe os seres humanos apenas como um fio particular na teia da vida." (CAPRA, 1996, p. 17)

Por fim, autores da crítica marxista recusam a tendência de sustentabilidade ambiental vinculada à noção "conservadora", propondo a perspectiva "transformadora" (FREITAS; NÉLSIS; NUNES, 2012, p. 43-44). Somente a superação da lógica capitalista de produção é que poria fim à crise que não se restringe ao meio ambiente, mas se estende por toda organização social. Caberia à tarefa de ordem superestrutural para alterar a infraestrutura. Uma profunda mudança de mentalidade seria necessária. ${ }^{13}$

Diante daquilo que chamamos de crise ambiental, grande parte dos autores aqui citados veem, como parte da saída, a necessidade da implementação de algo "novo". Seja pela "nova ética" de Berna, pela "mudança de mentalidade" de Reigota, pela "simetria" de Latour, pelo "novo modelo ou matriz normativa" de Grün, pela "ecologia profunda" de Capra, pela revolução do pensamento marxista, entre outras, levanta-se a urgência da mudança em direção a algo novo, diferente do hegemônico. Tais autores, cada qual sob seus específicos prismas,

\footnotetext{
13 Vale mencionar que vários historiadores já se debruçaram sobre a questão do tempo histórico e das transformações contidas nele. Entre permanências e mudanças, continuidades e rupturas, há distintas dimensões do tempo. Segundo Fernand Braudel (1983) e Ronaldo Vainfas (1997), as mentalidades correspondem ao tempo de longa duração e são modelos estruturais que custam a esboçar qualquer mudança. Assim, compreendemos que as mudanças postuladas por ampla maioria de autores que tratam da questão ambiental podem levar séculos para ocorrer.
} 
postulam a necessidade de mudança. A esperança de que a projeção de novos modos distintos de olhar para a natureza tem mobilizado os autores de diversas áreas na atuação por um mundo melhor, mais equilibrado e justo. A implementação do "novo" é praticamente um consenso por entre aqueles que identificam a necessidade de uma ruptura com a mentalidade ideológica hegemônica. As divergências consistem, basicamente, em qual "novo" seria esse e de que modo ele seria implementado.

No entanto, quero me ater brevemente à possibilidade de algo que não se enquadra exatamente ao que poderíamos chamar de "novo", tampouco é "velho"; mas perpassa por toda a história e resiste até os nossos dias. Os povos originários daquilo que convencionou-se chamar de "América" trazem consigo outras perspectivas de relação com a Terra. A transformação da natureza em recurso econômico está longe de ser pensada entre os ameríndios e permanece posta em prática no manejo das áreas reservadas para seu uso. Trata-se de uma outra possibilidade de relacionamento entre homem e natureza, uma verdadeira antítese à hegemonia presente no ocidente.

Em 1855 foi redigida uma carta que se tornaria mais famosa com o passar dos anos. $\mathrm{O}$ grande chefe Seattle escrevia para o então presidente dos Estados Unidos da América, Franklin Pierce, ou "chefe de Washington", como foi tratado na carta. A fama da carta ocorreu de forma progressiva, na medida em que a luta pelo reconhecimento dos direitos dos povos originários da América cresceu e, nas últimas décadas, por se perceber que se tratava de uma outra concepção de natureza. A veemência com que as palavras são postas na carta revela o contraste entre dois mundos tão distantes, percepções tão distintas. A ironia se faz presente por todo texto, uma vez que o cacique assume-se como um selvagem e acaba trazendo uma série de ensinamentos para o homem branco dito civilizado. Dessa forma, parágrafo após parágrafo, denuncia a selvageria do próprio homem branco e a civilidade indígena. A terra, os rios, os animais e plantas fazem parte de um todo uno, que traz sentido a existência dos Duwamish. Seria impossível vender a terra, simplesmente por ser impensável vendê-la, uma vez que ela não é uma mercadoria, um recurso. ${ }^{14}$

Não é à toa que, ao relembrar um encontro com um rapaz mestiço em La Paz, Carlos Rodrigues Brandão relata o estranhamento da visão de mundo indígena com relação aos

\footnotetext{
${ }^{14}$ Em termos semelhantes, Davi Kopenawa expõe sua perspectiva sobre o fetichismo do homem branco e sua paixão por tudo aquilo que é apropriado da natureza e feito mercadoria (KOPENAWA; ALBERT, 2015, p. 406420).
} 
brancos. Sobre o pensamento "ocidental", o rapaz afirma: "Os brancos pensam tudo opondo uma coisa à outra. [...] Os índios da minha gente pensam as mesmas coisas ao contrário. [...] Os brancos parecem que só se sentem vivendo no que possuem" (BRANDÃO, 1994, p. 16-17). O texto segue por páginas expondo quais as concepções de mundo indígena, seus entendimentos acerca da terra, contrapondo-se à limitada visão antropocêntrica, e termina fazendo um convite pra sermos "irmãos do universo", não "senhores do mundo" (p. 41).

O "resgate" da perspectiva indígena para pautar uma "nova" concepção de sociedade com a natureza tem recebido críticas de setores mais conservadores, e mesmo daqueles que admitem a necessidade de mudança. A argumentação consiste em afirmar que se negam as conjunturas históricas nas quais estamos assentados e idealiza-se um "retorno" ao passado (SHEPARD, 1992, p. 41; GRÜN, 2009, p. 76). São alegações pertinentes; contudo, permanecem atreladas à ideia de história linear e única. Levar a cabo a sabedoria indígena não significa romper com a historicidade e negar a atual conjuntura, mas em considerar que a história presente também é a história dos povos indígenas. Talvez tenha chegado a hora de simplesmente pararmos de elaborar nossas teorias e hipóteses sobre o futuro e sentar para escutar o que os Yanomami, Xavante, Guajajara, Kiriri e tantos outros povos indígenas têm a nos ensinar.

\section{Considerações finais}

Do ponto de vista de políticas públicas, o Brasil vive um período que ruma na contramão da integração do pensamento indígena ao restante da sociedade, quando se busca integrar os povos indígenas ao que costumeiramente chama-se de "civilização", segundo programa de governo de Jair Bolsonaro. A integração do indígena se dá de modo unilateral e segundo os interesses econômicos pelas reservas pertencentes à União, mas de posse permanente dos povos originários. Não se tem como questão central quais os desejos dos donos da terra, simplesmente, porque não se ouve aquele que é tratado como inferior. Os desmontes da estrutura Estatal e o esfacelamento de direitos conquistados e reconhecidos cresce a cada dia. O notório desprezo pelo meio ambiente é parte significativa do desejo incalculável pelo progresso (e o enriquecimento ou acumulação) a qualquer custo. Ao que tudo indica serão tempos sombrios, mas tempos de luta, como já têm sido. 
Grandes responsáveis pela preservação de importante contingentes da fauna e da flora brasileiras, os povos tradicionais são a vanguarda da resistência aos projetos desenvolvimentistas e de supressão da diversidade. A luta pelo ambiental não está isolada, mas se hibridiza junto das lutas sociais. Nessa linha de pensamento, o "ambientalismo" não é visto como desconexo das demais relações sociais, mas

\begin{abstract}
merecem relevo aspectos como a articulação entre ambientalismo e outros movimentos populares, a incorporação da problemática social no debate ambientalista, a rejeição do ambientalismo de caráter pragmático e de visão utilitarista, a luta pela reorganização política mundial e a conquista de espaços representativos na sociedade civil e nos aparelhos de Estado, de forma que a mobilização venha a transformar-se efetivamente em movimento histórico, coerente e articulado (LOUREIRO, 2002, p. 19).
\end{abstract}

Assim, é partindo de uma perspectiva socioambiental que visa unir a fratura entre sociedade e natureza, trazendo as permanências do conhecimento milenar ameríndio como uma das "novas" possibilidades para solucionar da crise contemporânea global e, sobretudo, lembrando da vivacidade da luta indígena, que fecho as reflexões aqui presentes. Por fim, espero que, por meio delas, possamos considerar os fundamentos histórico-filosóficos da cultura hegemônica em busca de alternativas para a problemática ambiental. Sem, no entanto, desconsiderar que talvez a mais promissora das soluções para a crise possa vir de outros modos de vida distantes dos nossos círculos teóricos e de debates acadêmicos. Conforme dito por Sônia Guajajara (2019): “A sabedoria ancestral é a salvação do planeta!”15

\title{
Referências
}

ARISTÓTELES. Política. Trad. Pedro C. Tolens. São Paulo: Editora Martin Claret, 2007.

AGOSTINHO, Santo. O livre arbítrio. São Paulo: Paulus, 1995.

BERNA, Vilmar. Como fazer educação ambiental. São Paulo: Paulus, 2001.

BÍBLIA. Bíblia de Jerusalém. São Paulo: Paulus, 2002.

BOFF, Leonardo. Saber Cuidar: ética do humano - compaixão pela terra. Petrópolis: Vozes, 1999.

\footnotetext{
${ }^{15}$ Fala proferida na Comissão de Meio Ambiente e Desenvolvimento Sustentável ocorrida dia 25 de abril de 2019 na Câmara dos Deputados (disponível em: https://youtu.be/PRWlmaeQaM0?t=7646).
} 
BONTEMPO, Gínia César (org.). Assim na terra como no céu: experiências socioambientais na igreja local. Viçosa: Ultimato, 2011.

BRANDÃO, Carlos Rodrigues. Somos as águas puras. Campinas: Papirus, 1994.

BRAUDEL, Fernand. O Mediterrâneo e o mundo mediterrânico na época de Felipe II. São Paulo: Livraria Martins Fontes Editores, 1983..

CAPRA, Fritjof. A teia da vida. Uma nova compreensão científica dos sistemas vivos. São Paulo: Editora Cultrix, 1996.

DIAMOND, Jared. Colapso: como as sociedades escolhem o sucesso ou o fracasso. Rio de Janeiro: Record, 2005.

FOSTER, John Bellamy. A ecologia de Marx: materialismo e natureza. Rio de Janeiro: Civilização Brasileira, 2010.

FREITAS, R. C. M.; NÉLSIS, C. M.; NUNES, L. S. A crítica marxista ao desenvolvimento (in)sustentável. Revista Katálysis. v. 15, n. 1, p. 41-51, Florianópolis: UFSC, 2012.

GUAJAJARA, Sônia. Comissão de Meio Ambiente e Desenvolvimento Sustentável. Tema: "O papel dos povos indígenas na proteção do meio ambiente e desenvolvimento sustentável e as consequências da MPV 870/19". CÂMARA DOS DEPUTADOS. 2019. (02h07m25s). Disponível em: <https://youtu.be/PRWlmaeQaM0?t=7646>. Acesso em: 25 abril. 2019.

GRÜN, Mauro. Ética e Educação Ambiental: a conexão necessária. 12a ed. (Coleção Magistério: Formação e Trabalho Pedagógico). Campinas: Papirus, 2009.

HARRIS, Peter. A Rocha: uma comunidade evangélica luta pela preservação do meio ambiente. São Paulo: ABU Editora, 2001.

HARVEY, David. O novo imperialismo. $2^{\circ}$ edição. São Paulo: Edições Loyola, 2005.

HUNTINGTON, Samuel P. Choque de civilizações e a recomposição da ordem mundial. Rio de Janeiro: Objetiva, 1997.

JONES, James. Jesus e a Terra. Viçosa: Ultimato, 2018.

KOPENAWA, Davi; ALBERT, Bruce. A queda do céu: palavras de um xamã yanomami. Tradução: Beatriz Perrone-Moisés. Prefácio: Eduardo Viveiros de Castro. $1^{\mathrm{a}}$ edição. São Paulo: Companhia das Letras, 2015.

LATOUR, Bruno. Jamais fomos modernos: ensaio de antropologia simétrica. Rio de Janeiro: Editora 34, 1994.

LOUREIRO, Carlos Frederico Bernardo. O movimento ambientalista e o pensamento crítico: uma abordagem política. Rio de Janeiro: Quartet, 2006. 
Teoria Social e Questão Ambiental: pressupostos para uma práxis crítica em educação ambiental. In: LOUREIRO, C. F. B; LAYRARGUES, P. P; CASTRO, R. S. Sociedade e Meio Ambiente: a educação ambiental em debate. 3. Ed. São Paulo: Cortez, 2002.

LOUREIRO, C. F. B.; COSSIO, M. F. B. Um olhar sobre a educação ambiental nas escolas: considerações iniciais sobre os resultados do projeto 'O que fazem as escolas que dizem que fazem educação ambiental?'. In: MELLO, S. S.; TRAJBER, R. Vamos cuidar do Brasil: conceitos e práticas em educação ambiental na escola. Brasília: Ministério da Educação, UNESCO, 2007.

MARX, Karl. Manuscritos econômico-filosóficos: primeiro manuscrito. 1844. Disponível em: <https://www.marxists.org/portugues/marx/1844/manuscritos/>. Acesso em: 25 abr. 2019.

. O capital: crítica da economia política. Livro I, Vol. 2. Tradução de Reginaldo Sant'Anna. 24a edição. Rio de Janeiro: Civilização Brasileira, 2006.

MELO, Demian Bezerra. Revisão e revisionismo historiográfico: os embates sobre o passado e as disputas políticas contemporâneas. In: Marx e o Marxismo. v.1, n.1, jul/dez 2013.

MÉSZÁROS, István. A crise estrutural do capital. Tradução: Francisco Raul Cornejo... [et al.]. $2^{a}$ edicção rev. e ampliada. São Paulo: Boitempo, 2011.

MONGE, Yolanda. Trump sobre relatório climático do seu Governo: "Não acredito". In: $E l$ País. Washington: 27 nov. 2018. Caderno Internacional, Meio Ambiente. Disponível em: < https://brasil.elpais.com/brasil/2018/11/27/internacional/1543283242_634443.html>. Acesso em: 15 de março de 2019.

MONTIBELLER FILHO, Gilberto. O mito do desenvolvimento sustentável. Tese (Doutorado Interdisciplinar em Ciências Huamanas. Área de concentração: Sociedade e Meio Ambiente) - Centro de Filosofia e Ciências Humanas, Universidade Federal de Santa Catarina. Florianópolis, p. 255. 1999.

MORAES, Antonio Carlos Robert. Geografia: pequena história crítica. 20ª ed. São Paulo: Annablume, 2005.

NAVARRO, Alexandre Guida. A civilização maia: contextualização historiográfica e arqueológica. In: História [online]. vol.27, n.1, p. 347-377. São Paulo: Unesp, 2008.

OLIVEIRA, Manfredo; ALMEIDA, Custódio. O Deus dos filósofos modernos. vol. 1. $2^{\mathrm{a}}$ ed. Petrópolis: Editora Vozes, 2003.

PELICIONI, Maria Cecília Focesi. Educação Ambiental, Qualidade de Vida e Sustentabilidade. In: Saúde e Sociedade. (online) vol. 7, n. 2, p. 19-31, 1998.

QUINTANA, Ana Carolina; HACON, Vanessa. O desenvolvimento do capitalismo e a crise ambiental. In: O Social em Questão. Ano XIV - nº 25/26, 2011. 
REALE, Giovanni; ANTISERI, Dario. História da filosofia: do romantismo ao empiriocriticismo. Vol. 5. (Coleção história da filosodia). São Paulo: Paulus, 2005.

REIGOTA, Marcos. Meio ambiente e representação social. São Paulo: Cortez; 1995.

SHEPARD, Paul. A post-historic primitivismo. In: OELSCHLAEGER, Max (org.). The wilderness condition: essays on environmental and civilization. Washington: Island Press, 1992.

SKINNER, Quentin. As fundações do pensamento político moderno. São Paulo: Companhia das Letras, 1999.

THOMAS, Keith. O Homem e o Mundo Natural: mudanças de atitude em relação às plantas e aos animais (1500-1800). São Paulo: Companhia das Letras, 1988.

TRAVERSO, Enzo. "Revisión y Revisionismo". In El Pasado: instrucciones de uso. Historia, memoria, política. Madrid/Barcelona: Marcial Pons, Ediciones Jurídicas y Sociales S.A., 2007.

TRUMP, Donald John. Brutal and Extended Cold Blast could shatter ALL RECORDS Whatever happened to Global Warming? 21 de novembro de 2018. Twitter: @ realDonaldTrump. Disponível em:

<https://twitter.com/realdonaldtrump/status/1065400254151954432>. Acesso em: 2 de fevereiro de 2019.

VAINFAS, Ronaldo. História das Mentalidades e História Cultura. In: CARDOSO, Ciro Flamarion; VAINFAS, Ronaldo (orgs.). Domínios da história: ensaios de teoria e metodologia. Rio de Janeiro: Campus, 1997.

WEBER, Max. A Ética Protestante e o Espírito do Capitalismo. São Paulo: Editora Martin Claret, 2007.

WHITE JR, Lynn. The Historical Roots of Our Ecologic Crisis. In: Science. Vol. 155, 1967. 